\title{
Comparative abrasive wear resistance and surface analysis of dental resin-based materials
}

\author{
Maleeha Nayyer ${ }^{1}$, Shahreen Zahid ${ }^{1}$, Syed Hammad Hassan ${ }^{1,2}$, Salman Aziz Mian ${ }^{3}$, \\ Sana Mehmood ${ }^{4}$, Haroon Ahmed Khan ${ }^{5}$, Muhammad Kaleem ${ }^{1}$, \\ Muhammad Sohail Zafar ${ }^{6,7}$, Abdul Samad Khan ${ }^{8}$
}

Correspondence: Dr. Muhammad Sohail Zafar

Email: drsohail_78@hotmail.com

\begin{abstract}
'Department of Dental Materials, Army Medical College, National University of Medical Sciences, Rawalpindi, Pakistan,

${ }^{2}$ Department of Prosthodontics, Armed Forces Institute of Dentistry, National University of Medical Sciences, Rawalpindi, Pakistan,

${ }^{3}$ Department of Dental Materials, Institute of Dentistry, CMH Lahore Medical College, Lahore, Pakistan, ${ }^{4}$ Interdisciplinary Research Centre in Biomedical Materials, COMSATS Institute of Information Technology, Lahore, Pakistan,

${ }^{5}$ Department of Electrical Engineering, COMSATS Institute of Information Technology, Islamabad, Pakistan, ${ }^{6}$ Department of Restorative Dentistry, College of Dentistry, Taibah University, Madinah Munawwarah, Saudi Arabia, ${ }^{7}$ Department of Dental Materials, Islamic International Dental College, Riphah International University, Islamabad, Pakistan,

${ }^{8}$ Department of Restorative Dental Sciences, College of Dentistry, Imam Abdulrahman Bin Faisal University, Dammam, Saudi Arabia
\end{abstract}

\section{ABSTRACT}

Objective: The objective of this study was to assess the surface properties (microhardness and wear resistance) of various composites and compomer materials. In addition, the methodologies used for assessing wear resistance were compared. Materials and Methods: This study was conducted using restorative material (Filtek Z250, Filtek Z350, QuiXfil, SureFil SDR, and Dyract XP) to assess wear resistance. A custom-made toothbrush simulator was employed for wear testing. Before and after wear resistance, structural, surface, and physical properties were assessed using various techniques. Results: Structural changes and mass loss were observed after treatment, whereas no significant difference in terms of microhardness was observed. The correlation between atomic force microscopy (AFM) and profilometer and between wear resistance and filler volume was highly significant. The correlation between wear resistance and microhardness were insignificant. Conclusions: The AFM presented higher precision compared to optical profilometers at a nanoscale level, but both methods can be used in tandem for a more detailed and precise roughness analysis.

Key words: Abrasion, atomic force microscopy, dental materials, Fourier transform infrared, surface roughness

\begin{tabular}{|l|l|}
\hline \multicolumn{3}{|c|}{ Access this article online } \\
\hline Quick Response Code: & \\
\hline
\end{tabular}

This is an open access article distributed under the terms of the Creative Commons Attribution-NonCommercial-ShareAlike 3.0 License, which allows others to remix, tweak, and build upon the work non-commercially, as long as the author is credited and the new creations are licensed under the identical terms.

For reprints contact: reprints@medknow.com

How to cite this article: Nayyer M, Zahid S, Hassan SH, Mian SA, Mehmood S, Khan HA, et al. Comparative abrasive wear resistance and surface analysis of dental resin-based materials. Eur J Dent 2018;12:57-66. DOI: 10.4103/ejd.ejd_380_17 


\section{INTRODUCTION}

Wear refers to the progressive loss of material from the surface of teeth or restorative materials as a result of chemical and mechanical processes such as erosion and abrasion. ${ }^{[1]}$ Within the context of the oral cavity, wear is a complex phenomenon. Wear by toothbrushing falls into the category of the three-body wear and is most commonly observed on facial surfaces of teeth and dental restorations. ${ }^{[2]}$ Resistance to abrasive wear is an important property of a dental material. It determines the longevity of the material in clinical service. ${ }^{[3]}$ Surface roughness has a major influence on the esthetic appearance and discoloration of restorations. Microorganisms adhere strongly to rough surfaces, thereby promoting plaque accumulation, caries, and gingival inflammation. ${ }^{[4]}$ Ideal dental restorations should have wear resistance similar to that of tooth. ${ }^{[5]}$ However, till date, wear in composites remains a major concern. The values of average clinical wear on occlusal surfaces of composite restorations approximates to about $29 \mu \mathrm{m}$ per year for molars and $15 \mu \mathrm{m}$ for premolars. Substantially higher values are reported for proximal wear. ${ }^{[6]}$

Considerable improvements have been made in terms of mechanical properties of dental composite resins. ${ }^{[7]}$ Several aspects of the composition and structure of composite resins directly affect and limit wear resistance. ${ }^{[8]}$ There is a paradigm shift in restorative dentistry with the synthesis of new polymeric systems and the introduction of the inorganic nanofillers. ${ }^{[9,10]}$ Manufacturers usually make unsubstantiated claims about the wear resistance of the composite resins. To test manufacturer's claims, an in vitro test method was adopted to evaluate mass loss and surface roughness. ${ }^{[11]}$ In vivo methodologies are generally very time-consuming and hard to accurately reproduce. ${ }^{[12]}$ Therefore, for the present study, an in vitro testing method was employed. The objective of this study was 2-fold, one was to assess the different types of commercially available composites and compomer materials - based on surface properties such as structural changes, microhardness, and corresponding wear resistance. The second was to compare the methodologies used for assessing wear resistance.

\section{MATERIALS AND METHODS}

In this study, five different types of commercially available materials microhybrid [Filtek ${ }^{\mathrm{TM}} \mathrm{Z250}$ XT, 3M ESPE, Germany], nanocomposites [Filtek ${ }^{\mathrm{TM}} \mathrm{Z} 350 \mathrm{XT}$, 3M ESPE, Germany], packable [QuiXfil, Dentsply, Germany], flowable [Surefull SDR, Dentsply, Germany], and compomer [Dyract ${ }^{\circledR} \mathrm{XP}$, Dentsply, Germany] were selected and their composition is given in Table 1.

\section{Sample preparation}

Samples with $10 \mathrm{~mm} \times 2 \mathrm{~mm}$ dimension were prepared in Teflon mold for each material. Specimens were prepared in a single insertion and compacted using glass slides on both sides. Samples were thoroughly cured from both sides with $4000 \mathrm{~mW} / \mathrm{cm}^{2}$ irradiance for 60 s from each side (Flash Max P4 Ortho, Colorado, USA 1503078). The samples were polished by carefully trimming any excess with a 1200 -grit silicon carbide sheets and using an automatic polishing

\begin{tabular}{|c|c|c|c|c|c|c|}
\hline $\begin{array}{l}\text { Product } \\
\text { name }\end{array}$ & Type & Manufacturer & Lot & Fillers & $\begin{array}{c}\text { Filler } \\
\text { volume (\%) }\end{array}$ & Monomers* \\
\hline $\begin{array}{l}\text { Filtek }^{\mathrm{TM}} \\
\text { Z250 XT } \\
(\mathrm{Z} 250)\end{array}$ & $\begin{array}{l}\text { Universal } \\
\text { microhybrid } \\
\text { composite }\end{array}$ & $\begin{array}{l}\text { 3M ESPE, } \\
\text { Germany }\end{array}$ & N703519 & $\begin{array}{l}\text { Zirconia/silica particle size } \\
\text { range } 0.01-3.5 \mu \mathrm{m}\end{array}$ & 50 & $\begin{array}{l}\text { Bis-GMA, UDMA, } \\
\text { Bis-EMA }\end{array}$ \\
\hline $\begin{array}{l}\text { Filtek }^{\mathrm{TM}} \\
\text { Z350 XT } \\
(\mathrm{Z} 350)\end{array}$ & Nano-composite & $\begin{array}{l}\text { 3M ESPE, } \\
\text { Germany }\end{array}$ & N660853 & $\begin{array}{l}\text { Combination of } 0.004-0.02 \mu \mathrm{m} \\
\text { nonagglomerated zirconia/silica particles } \\
\text { and agglomerated } 0.60-1.40 \mu \mathrm{m} \text { clusters }\end{array}$ & 57 & $\begin{array}{l}\text { Bis-GMA, UDMA } \\
\text { TEGDMA, } \\
\text { PEGDMA, Bis-EMA }\end{array}$ \\
\hline $\begin{array}{l}\text { QuiXfil } \\
\text { (QFL) }\end{array}$ & $\begin{array}{l}\text { Fast-setting, } \\
\text { packable } \\
\text { composite }\end{array}$ & $\begin{array}{l}\text { Dentsply, } \\
\text { Germany }\end{array}$ & 1503000064 & $\begin{array}{l}\text { Strontium glass fractions in two sets } \\
\text { ranging from particle size } 1-4 \mu \mathrm{m}\end{array}$ & 66 & $\begin{array}{l}\text { Bis-EMA, UDMA, } \\
\text { TCB TEGDMA, } \\
\text { TMPTMA }\end{array}$ \\
\hline $\begin{array}{l}\text { Surefil } \\
\text { SDR }\end{array}$ & $\begin{array}{l}\text { Low viscosity, } \\
\text { flowable } \\
\text { composite }\end{array}$ & $\begin{array}{l}\text { Dentsply, } \\
\text { Germany }\end{array}$ & 1503000686 & Nano-filled $\mathrm{Ba} / \mathrm{Si}$ alumino fluorosilicate & 45 & UDMA, TEGDMA \\
\hline $\begin{array}{l}\text { Dyract }{ }^{\circledR} X P \\
\text { (Dyract) }\end{array}$ & Compomer & $\begin{array}{l}\text { Dentsply, } \\
\text { Germany }\end{array}$ & 1502000426 & $\begin{array}{l}\text { Strontium-flouro silicate glass mean } \\
\text { filler size } 0.8 \mu \mathrm{m}\end{array}$ & 47 & UDMA, TCB \\
\hline
\end{tabular}


machine (Metkon GRIPO2V Grinder Polisher, Turkey), followed by sonication to remove residue of polishing. Afterward, each specimen was conditioned in distilled water for 7 days at $37^{\circ} \mathrm{C}$, according to the conditioning described for abrasive wear test IS0/TR 14569. The samples were then air-dried for an hour. Readings for all tests were recorded before and following the abrasive wear test.

\section{Fourier-transform infrared spectroscopy}

To find the structural changes, spectroscopic analysis of all samples was conducted before and after treatment. For each sample before and after treatment, 10 spectra were taken to find out the spectral difference. Thermo Nicolet 6700 (USA) was used with attenuated total reflectance as accessory. The resolution was $8 \mathrm{~cm}^{-1}$ with 256 scan number. The spectral range was $4000-$ $600 \mathrm{~cm}^{-1}$. OMNIC software (Thermo Fisher Scientific wissenschaftliche Geräte $\mathrm{GmbH}$, Austria)was used to analyze the spectra.

\section{Principal component and cluster analysis}

Chemometric methods were used to quantify the spectral differences of various composite groups, i.e., untreated Dyract, untreated QFL, untreated SDR (US), untreated Z250 (U2), untreated Z350 (U3), treated Dyract, treated QFL, treated SDR (TS), treated Z250 (T2), and treated Z350 (T3). These methods were performed using Unscrambler X 10.2 software, purchased from Camo software (Oslo, Norway). Preprocessing comprised of baseline correction and unit vector normalization. Cluster analysis (CA) was performed over complete spectral range by Ward's method using squared Euclidean distance.

\section{Microhardness testing}

For a comparison of selected materials before and after simulated toothbrushing, microhardness was analyzed in terms of Vickers hardness number. Using a $200 \mathrm{~g}$ load with 10s dwell time (Microhardness tester, WOLPERT, 401MVD EQPT 0002, Germany). Six samples from each group were used and each specimen was indented three times at three different points, and then the mean reading was recorded.

\section{Weight analysis}

Before the abrasive test, samples were weighed using an analytical electronic balance (Sartorius AG Gottingen BP 110 S, Germany) with accuracy up to $0.1 \mathrm{mg}$. In this way, initial mass $\left(\mathrm{M}_{1}\right)$, for each sample was obtained. Following the abrasive wear test, the samples were carefully removed, rinsed in tap water, and placed in an ultrasonic water bath (Cole-Parmer, Vernon Hills, Illinois, USA) for $1 \mathrm{~min}$. The samples were then individually removed, air-dried, and weighed. In this way, final mass $\left(\mathrm{M}_{2}\right)$ was obtained for each sample and mass loss (\%) was reported for each material post abrasion using following equation:

$\mathrm{W} \%=\left(\left[\mathrm{M}_{2}-\mathrm{M}_{1}\right] / \mathrm{M}_{1}\right) \times 100 \%$

\section{Surface roughness analysis}

Initial surface roughness was assessed using a noncontact mode 2D Profilometer (PS-50 Nanovea, Russia) and using a 3D-Atomic Force Microscope (AFM SPM-9500J3, Shimadzu Corp, Japan), operating in tapping mode. Micrographs were obtained at different scan areas measuring $20 \mu \mathrm{m} \times 20 \mu \mathrm{m}$ using AFM software (SPM-0ffline Shimadzu Corp. Japan). The roughness average, $\mathrm{Ra}$, is the most widely used one-dimensional (1D) roughness parameter, and it denotes the arithmetic mean of the absolute values of the collected roughness data points. $\mathrm{Ra}_{\mathrm{i}}$ (initial values) were taken and means were obtained. Surface roughness $\left(\mathrm{Ra}_{\mathrm{f}}\right)$ was measured after the abrasion wear test in the same way as for initial values, except that the tracing arm of profilometer and tip of AFM were positioned in such a way that the tracing direction was perpendicular to the direction of tooth brushing action. 3D images were reported in area selection of $10 \mu \mathrm{m} \times 10 \mu \mathrm{m}$.

\section{Abrasive wear test}

For the abrasive wear test, a custom-made toothbrush simulator was constructed in accordance with ISO11609: 2010, equipped with six stations of replaceable brush heads (Oral B Flat end). Tooth brushing load of $1.5 \mathrm{~N}$ was set. To mimic the original condition of toothpaste (Colgate-Palmolive, Dublin, Ireland), slurry was made with distilled water in the proportion 1:2. Resin-based samples were mounted in impression compound and placed in metallic stations. Toothbrushing was accomplished with horizontal movements of toothbrush and travelled a course of $4.2 \mathrm{~cm}$. Time duration was kept $100 \mathrm{~min}$ amounting to about 12,250 strokes was set. Toothbrushing time of 1.3 years was simulated. With these parameters, a minimum weight loss of $2 \mathrm{mg}$ by reference material, as described in IS0/TR 14569, was achieved. The slurry and brush heads were replaced for each sample.

\section{Data analysis}

The data were submitted to the analysis of variance (ANOVA) and post hoc Tuckey's Test, using 
IBM SPSS statistics version 21, Boston, Massachusetts, USA. The Pearson's test was used to verify the correlation between Roughness averages reported by AFM and Profilometer. In addition, the correlation of roughness alteration with filler volume and microhardness was also determined.

\section{RESULTS}

\section{Fourier-transform infrared spectroscopy}

Fourier-transform infrared (FTIR) spectra of samples (Z250, Z350, QFL, SDR, and Dyract) were collected before and after treatment as shown in Figure 1a-e.
The spectra of untreated samples showed $\mathrm{C}=\mathrm{O}$ stretching vibration peaks at $1710-1715 \mathrm{~cm}^{-1}$, peak at $1653 \mathrm{~cm}^{-1}$ and $1633 \mathrm{~cm}^{-1}$ attributed to C-C symmetric stretching appeared in all samples except SDR as aromatic group is not present in this composite. Peak at $1510 \mathrm{~cm}^{-1}$ corresponded to N-H bending vibrations of urethane-based resins. $\mathrm{C}-\mathrm{H}$ bend was observed at $1462 \mathrm{~cm}^{-1}$. The overlapping peaks at around $1250-900 \mathrm{~cm}^{-1}$ were due to asymmetric stretching vibration of $\mathrm{C}-\mathrm{O}-\mathrm{C}$ of monomer structure. Another sharp peak at $771 \mathrm{~cm}^{-1}$ was due to $\mathrm{C}-\mathrm{H}$ vibrations. After treatment, changes in peak intensities were observed for all samples specifically at $\mathrm{C}=\mathrm{O}$ and $\mathrm{N}-\mathrm{H}$ groups.

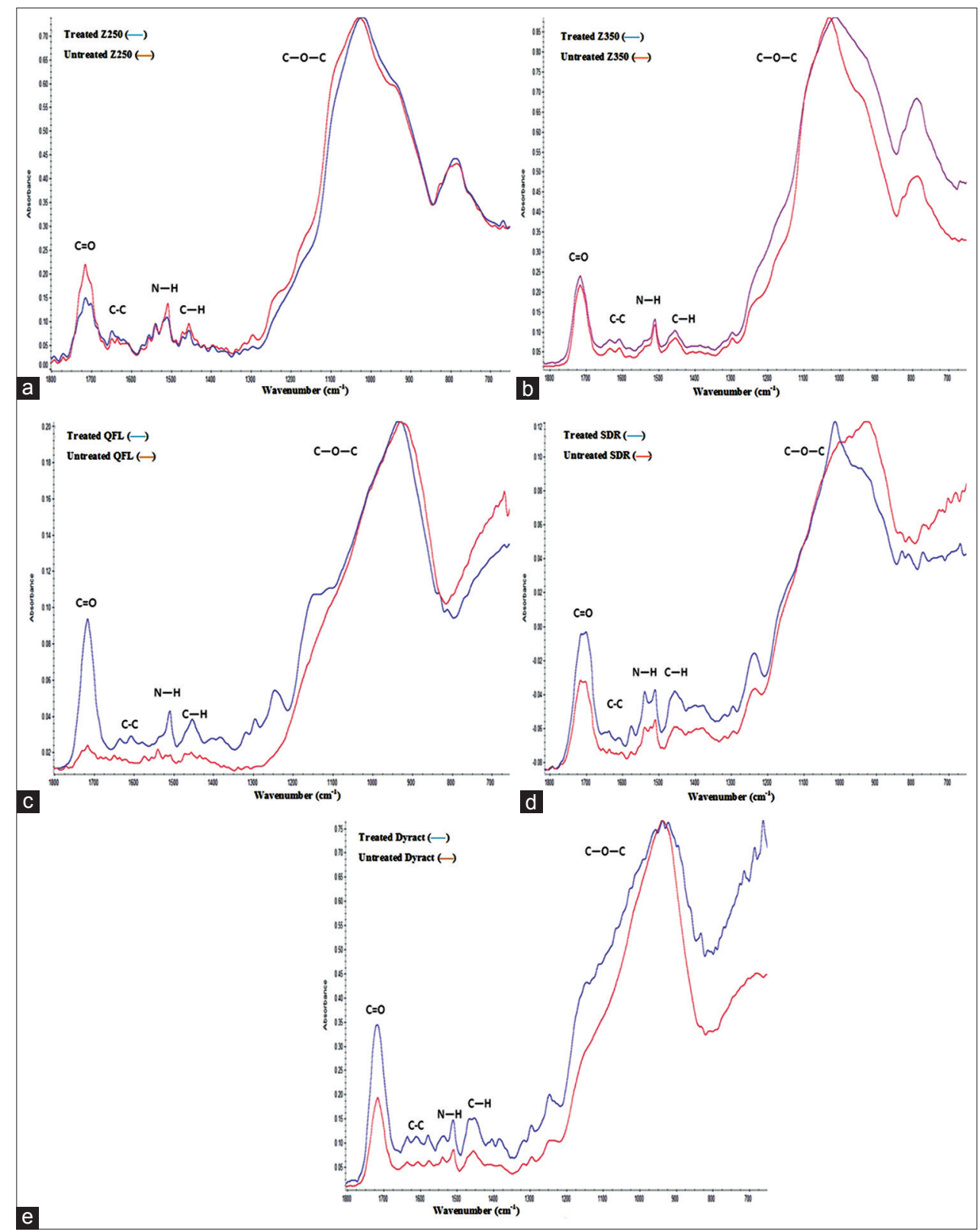

Figure 1: Comparative Fourier-transform infrared spectra of treated and untreated restorative materials; (a) Z250, (b) Z350, (c) QFL, (d) SDR, and (e) Dyract 


\section{Principal component analysis}

Principal component analysis (PCA) was performed and a comparison (spectral range; $700-3100 \mathrm{~cm}^{-1}$ ) was conducted between various treated and untreated dental composites as shown in Figure 2. Different comparative spectral ranges, $1660-1760 \mathrm{~cm}^{-1}, 1590-1650 \mathrm{~cm}^{-1}$, $1420-1470 \mathrm{~cm}^{-1}$, and $820-1220 \mathrm{~cm}^{-1}$ are given in Figure 3a-d, respectively. Complete spectral range displayed favorable separation of treated and untreated dental composites; PC1 separated all composites from TS with $97 \%$ variance, whereas the remaining $2 \%$ was

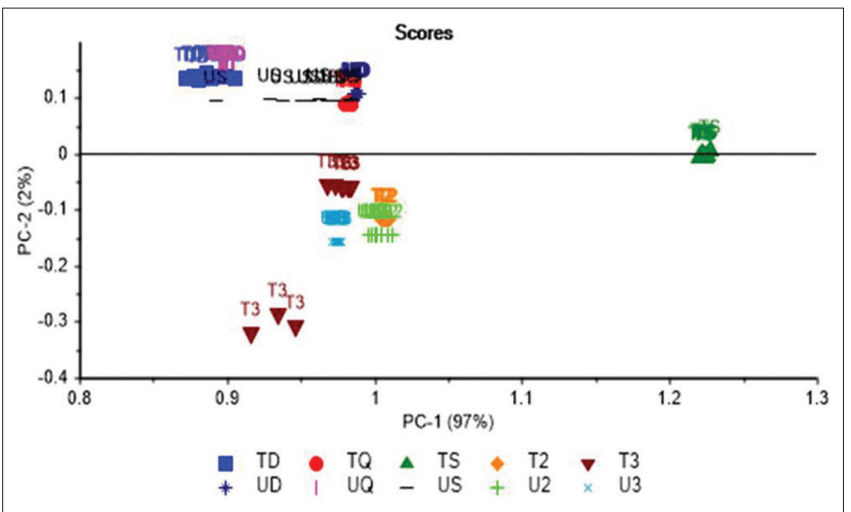

Figure 2: Principal component analysis of all treated and untreated composites over the complete spectral range observed in PC2 and 1\% in PC3 (figure not shown). All samples have shown distinct cluster formations to be recognizable as one group; however, US and T3 have demonstrated scattered formations hence suggesting inner group variability [Figure 2].

Similar trends were observed at $1660-1760 \mathrm{~cm}^{-1}$ region; however, the variance observed by $\mathrm{PC} 1$ was improved to $98 \%$ and the remaining $2 \%$ was detected by PC2. Within the treated and untreated composites, the sample groups can be well discriminated using PCA, whereas US and T3 showed variations within their respective groups [Figure 3].

By comparison, differences within the treated and untreated groups appeared to be much greater in the $1590-1650 \mathrm{~cm}^{-1}$ region, and the scores plot for this region showed good separation between all groups, i.e., 99\% for PC1. While the clusters were more widely spread, loading plots for PC1 and PC2 (data not shown) suggested the contrast in the peaks at this region to be a major influence. Within the treated and untreated samples at $1420-1470 \mathrm{~cm}^{-1}$ region, the sample groups can be well discriminated using PCA. PC1 and PC2, accounting for $100 \%$ of the variance, discriminated all samples on the basis of

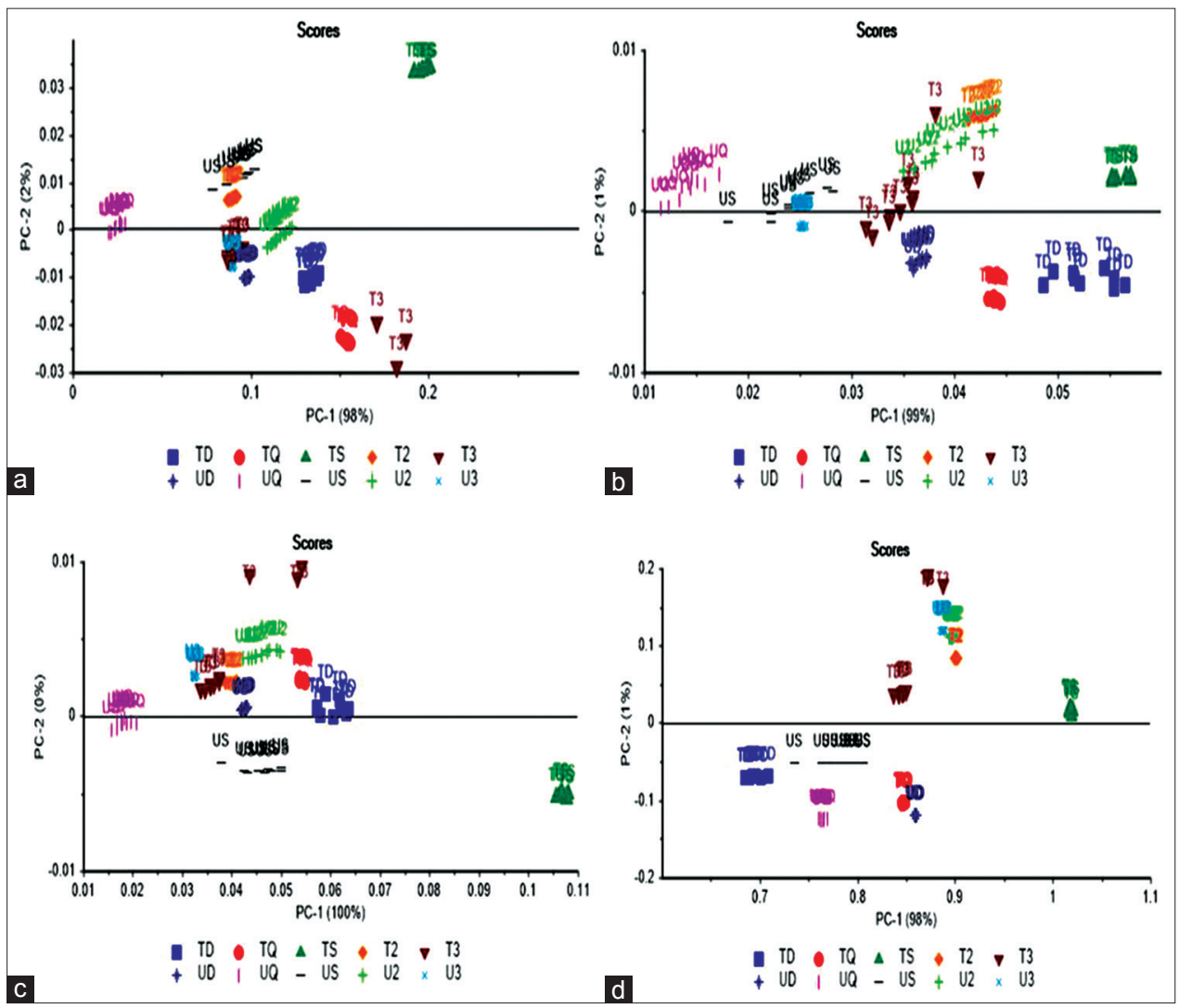

Figure 3: Principal component analysis of all treated and untreated composites over (a) $1660-1760 \mathrm{~cm}^{-1}$, (b) $1590-1650 \mathrm{~cm}^{-1}$, (c) $1420-1470 \mathrm{~cm}^{-1}$, and (d) $820-1220 \mathrm{~cm}^{-1}$ region 
their chemical content. The distribution of individual composite type in relation to the variance explained by PC1 produced clear and separated clusters for each of these samples. PCA between treated and untreated samples at $820-1220 \mathrm{~cm}^{-1}$ region showed that the variance explained by PC2 separated T2, U2, T3, and U3 from all other composite types, whereas PC1 distributed TS away from the others. Every composite type formed a separate cluster with the exception of US and T3 where PC1 demonstrated 98\% variance and PC2 $2 \%$ variance.

\section{Cluster analysis}

CA was performed over the complete spectral range $\left(700-3100 \mathrm{~cm}^{-1}\right)$. Figure 4 a showed the dendrogram of classification results for a dataset comprising of spectra collected from all untreated dental composites. Two distinct branches are formed where Z250 and Z350 were grouped together, whereas SDR, QFL, and Dyract have clustered separately. Altogether, each of the different composites formed well-defined clusters; however, SDR represented maximum relative distance hence suggesting most inner group variability. Figure $4 \mathrm{~b}$ showed the dendrogram of classification results for a dataset comprising of spectra collected from all treated dental composites.

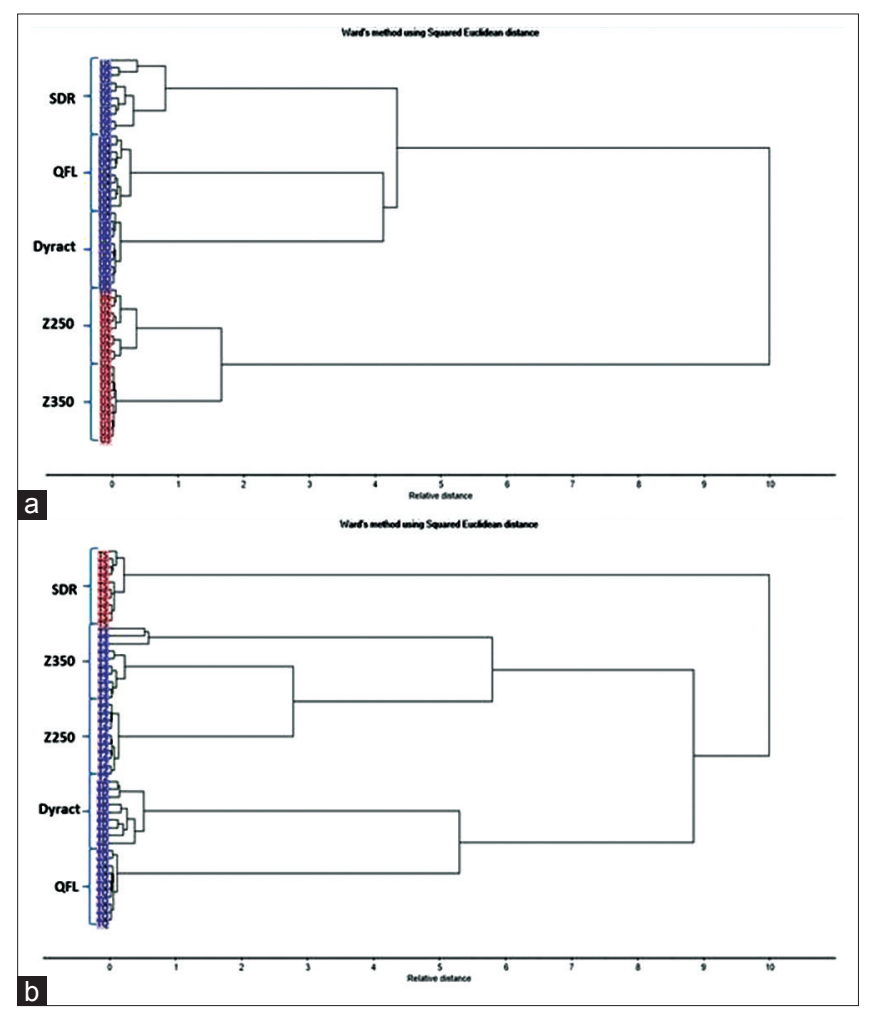

Figure 4: Component analysis of all (a) untreated and (b) treated samples over the complete spectral range
Two distinct branches are formed where SDR was clearly separated from the remaining treated composites. All sub-branches purely contained specific composite types with no one mixing with the other hence complementing the sensitivity of the technique. Dyract and Z350 demonstrated inner group variability of treated composites on the basis of maximum relative distance as compared to the rest.

\section{Hardness testing}

Comparison of microhardness among treated and untreated composite materials is tabulated in Table 2 . Dyract and QFL showed highest and lowest change, respectively, in microhardness compared to all the composite materials tested. A statistically significant change in microhardness was found between the groups after simulated toothbrushing $(P>0.05)$ by one-way ANOVA. Post hoc Tukey's test showed a significant difference between change in hardness of Dyract and QFL as well as Z350. There was also a significant difference between the results of QFL and SDR $(P>0.05)$. In the context of wear, all tested materials suffered significant mass loss $(P<0.05)$. Percentage mass loss of each material is graphically depicted in Figure 5. The maximum mass loss was observed in Z250 while Dyract showed the lowest mass loss. The mass loss observed in the case of SDR was significantly higher than the other tested composite materials $(P<0.01)$.

\section{Surface roughness}

Initially, all tested materials presented relatively low values of surface roughness, as polishing of all samples was performed before the abrasion test. However, as expected toothbrush abrasion caused visible nanoscale alterations on the surface of all samples, varying in extent, according to material as illustrated by 3D pre- and postabrasion test

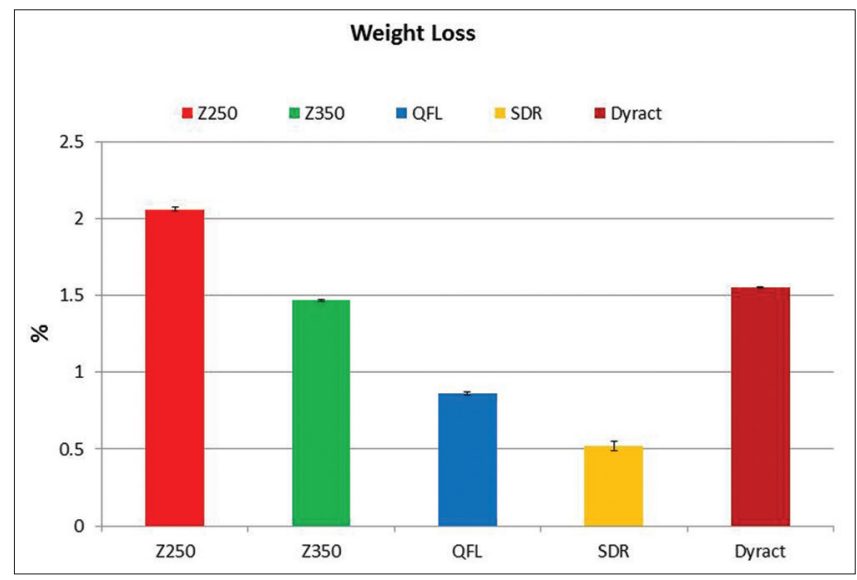

Figure 5: Average weight loss percentages of samples after treatment 
images obtained with the help of AFM [Figure 6a-e]. One-way ANOVA indicated that there was significant difference in the $\mathrm{R}_{\mathrm{a}}$ values between the groups $(P<0.05)$ using both AFM and optical profilometer.

The initial and final surface roughness values obtained with AFM and profilometer are illustrated graphically in Figure 7a and b, respectively. Following toothbrush abrasion, all tested materials presented a statistically significant increase in roughness values $(P<0.05)$. $\mathrm{Z} 25 \mathrm{O}$ presented with the highest $\mathrm{Ra}_{\mathrm{f}}$ value after abrasion test and also depicted the highest roughness alteration [Figure $7 \mathrm{a}$ and $\mathrm{b}$ ].

Dyract suffered highest mass loss the smoothest surface and the lowest $\mathrm{Ra}_{\mathrm{f}}$ value. Two-tailed Pearson's correlation was used to verify the correlation between AFM and optical profilometer, and it was found to be highly significant $(P<0.01)$. In addition, the correlation of roughness alteration (rate of wear) and

\begin{tabular}{lc}
$\begin{array}{l}\text { Table 2: Comparison of microhardness among the } \\
\text { tested materials }\end{array}$ \\
\hline Material & Mean microhardness (VHN) \\
\hline Dyract XP & $103.1 \pm 17.04$ \\
Filtek $^{\mathrm{TM}}$ Z250 & $92.93 \pm 11.21$ \\
Filtek $^{\mathrm{TM}}$ Z350 & $109.06 \pm 22.86$ \\
QuiXfil $^{-}$ & $100.3 \pm 13.73$ \\
Surefil (SDR) & $84.46 \pm 7.75$ \\
\hline VHN: Vickers hardness number, SDR: Smart dentin replacement
\end{tabular}
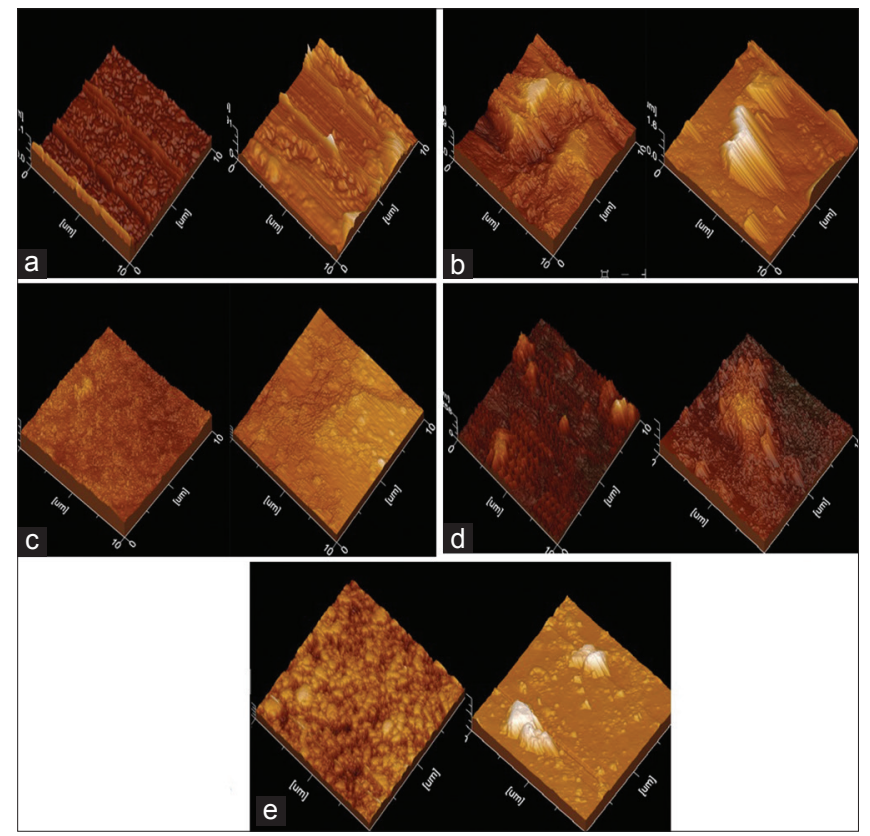

Figure 6: Three-dimensional atomic force microscopy images of restorative materials; (a) Z250, (b) Z350, (c) QFL, (d) SDR, and (e) Dyract, before (left) and after (right) treatment microhardness was found to be significant with filler volume $(P<0.05)$. The correlation between change in microhardness and surface roughness alterations of the tested materials with both methodologies, however, was not significant $(P>0.01)$.

\section{DISCUSSION}

In recent years, considerable improvements in the properties of dental composites have been made; however, wear of composite still remains a concern. ${ }^{[6]}$ In this aspect, the surface properties of restorative material play a major role in the long clinical life of restoration. In the oral cavity, wear is reflected by tearing away of organic matrix, exposure of inorganic content, and loss of smaller filler particles due to chewing and due to toothbrushing in our daily life. ${ }^{[13]}$ This surface roughness results in the loss of esthetics and also leads to an increase in accumulation of dental plaque and lodging of food particles, which coupled with bacterial adhesion, subsequently results in the destruction of restoration. ${ }^{[14]}$

In this study, along with the comparison of the wear of latest available materials, different available methodologies were used to analyze wear and correlation among these methodologies was found. For composite restorative materials, composition and filler morphology play a major role in its resistance

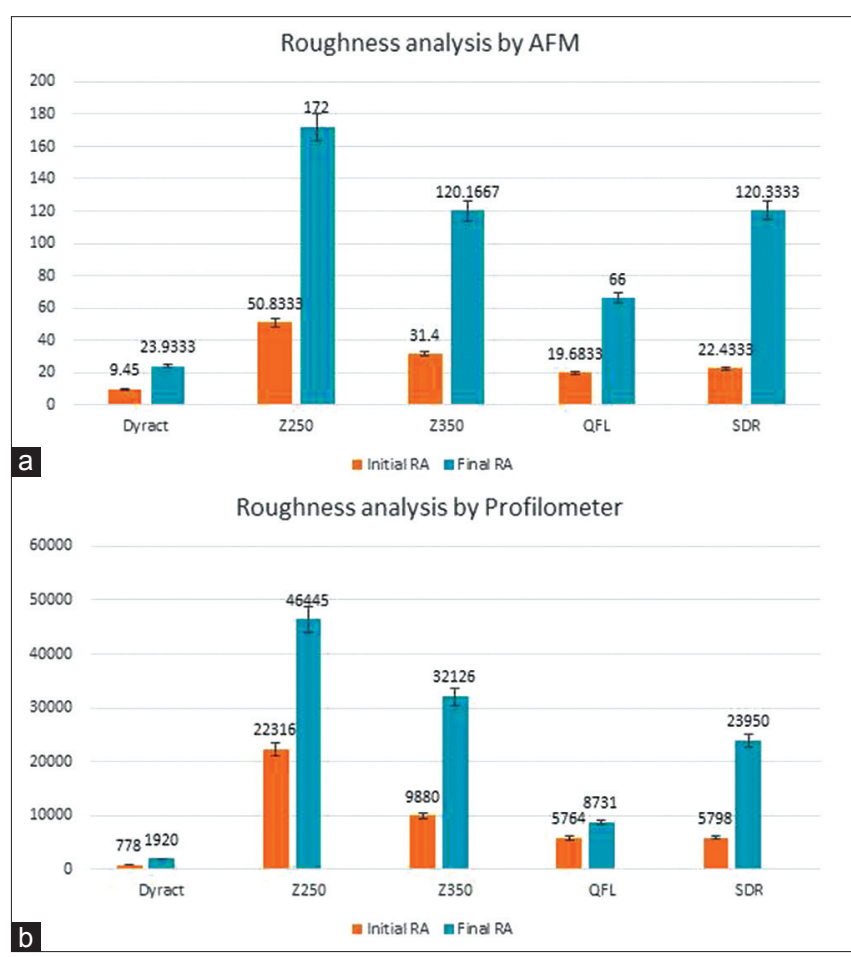

Figure 7: Surface roughness values of restorative materials using (a) atomic force microscopy and (b) optical profilometer 
against wear. ${ }^{[15]}$ The various materials selected for this study varied with respect to aforementioned variables.

Chemometric aids have demonstrated excellent sensitivity and specificity over the past two decades in various research areas from biological tissues to synthetic materials. These algorithms eliminate the chances of interobserver variability and provide true reflection of the data provided. PCA was chosen as a tool to investigate the spread of both treated and untreated dental composite groups and inner-group variation with various spectral regions selected based on the initial differences observed in the data. Although visual evaluation of the spectra showed similar peaks, each model presented as a separate cluster in PCA and CA. The clear separation between and within different dental composites suggested the substantial differences in the biochemical composition. Distinct characteristics were observed for SDR samples both in terms of inner-group variability as well as between groups. These results were consistent with the findings of FTIR data where the absence of C-C symmetric stretching was observed due to lack of aromatic groups. CA formed on the basis of molecular differences between the dataset showed separate branches in the dendrogram for each composite type. Both the treated and untreated revealed further discrete subsets representing each of the five composite types, and this discrimination suggested a high sensitivity of the technique. CA also supported the findings related to the absence of aromatic groups by classifying SDR in a separate branch of the dendrogram both in treated and untreated states.

The general concept is that, by measuring microhardness of material, a better understanding of the resistance of material against wear can be obtained. The measurement of microhardness theoretically implies that a hard surface will suffer less abrasive wear than a soft surface if other factors remain constant. However, previous studies showed controversial results, where it was reported that no significant interactions between hardness and wear. ${ }^{[4,16,17]}$ On the other hand, a significant relationship between hardness and wear has also been reported by Wang et al. ${ }^{[18]}$

Before toothbrushing simulation, SDR showed minimum microhardness values which were due to low filler content as compared to other composite materials. The results were in agreement with previous studies. ${ }^{[16,17]} \mathrm{Z} 350$ (nanocomposite) showed high hardness value compared to Z250 (microhybrid composite) which might be due to higher filler loading and higher surface area of filler particles, which have tendency to improve the interfacial linkage between resin-fillers. Postabrasion, Dyract and SDR presented with the greatest reduction in surface hardness which can be attributed to lower filler content compared to other materials. ${ }^{[17]}$ For Dyract, this might be due to the surface dissolution on contact with water, whereas Z350 and QFL presented with an increase in surface hardness after toothbrushing. This might be attributed to the surface deposition of dentifrice slurry on the surface of these materials. No change was observed in the surface hardness of Z250. However, the overall results of the present study did not find any significant correlation between changes in microhardness and wear resistance $(P>0.05)$.

Roughness average (Ra) is a well-accepted comparative feature, which quantifies surface texture by means of randomized readings of amplitude. ${ }^{[19]}$ In most previous studies, $\mathrm{Ra}_{\mathrm{f}}$ was interpreted as the only predictor of roughness and change in surface roughness which corresponds directly to rate of wear is usually not mentioned. A composite material with a high $\mathrm{Ra}_{\mathrm{i}}$ will also have a high $\mathrm{Ra}_{\mathrm{f}}$ The previous studies lacked in reporting the change in surface roughness and compared the two equipment (profilometer and AFM) on the basis of roughness values $\left(\mathrm{Ra}_{\mathrm{f}}\right)$ thus acting as a confounder.

The scale and resolution of the results generated by the profilometer and the AFM are not comparable. However, the results for each of the five groups being tested showed a similarity in trends in mutual comparison when it came to increasing $R_{a}$ for both testing techniques. ${ }^{[4,13]}$ The present study showed a significant correlation between the two contrary to a previous study which showed no correlation between the Ra values obtained using both techniques. ${ }^{[12,16]}$

Among composite material, QFL showed best results in terms of minimum change in roughness and final roughness average. Even though QFL showed the smoothest surface, but unlike compomers, it demonstrated lower mass loss. The mass loss was only more than SDR. The better wear resistance can be due to the higher filler volume along with better bonding between the filler and matrix component. The presence of triethylene glycol dimethacrylate (TEGDMA) can be another reason of better wear resistance as it enhances the filler-matrix interaction and improves polymerization which reduces the effect of water sorption. ${ }^{[20,21]}$ TEGDMA has a polyether backbone that increase its flexibility, ${ }^{[22]}$ and this may allow better molecular interaction and 
hence better polymerization. This results in increased degree of conversion reducing sorption and making the structure stiffer.

The minimum mass loss was recorded for the SDR, even though it presented with a greater change in roughness compared to Dyract and QFL. The minimum mass loss might be attributed to the presence of smaller particles and reduced interparticle spacing resulting in even distribution that favors the matrix against tearing completely. Greater mass loss in the case of Dyract and SDR complements the reduction in surface microhardness of these materials. However, for roughness changes, according to previous studies, higher filler-loading resulted in greater wear resistance. ${ }^{[23]}$ The presence of lower filler content of flowable composite than packable composites explained the higher change in roughness. Not only the filler volume but also the filler-particle size affects the wear resistance. ${ }^{[24]}$ Turssi et al. ${ }^{[25]}$ suggested that the presence of large particles theoretically cause greater abrasion. Increase in filler-particle size, causes an increase in the coefficient of friction, and stress spreads readily from the filler particles to the resin matrix, resulting in greater wear. In addition, wear affects the surface properties of materials such as hardness and elastic modulus. ${ }^{[26]}$ This was reflected in the comparison of particle sizes of microhybrid material Z250 and nanocomposites Z350. Due to higher surface area and surface energy, nanosized particles improve the performance of resin composites. ${ }^{[27,28]}$

On comparing the mass loss of Z350 with Z250, the former showed significantly lower than latter $(P<0.01)$. Z350 presented a smoother surface when compared with the Z250. This was due to the more homogenous distribution and greater volume of filler content of nanocomposites. ${ }^{[29]}$ Overall, Z250 presented with the greatest mass loss and roughest surface after toothbrush abrasion test. This was somewhat expected, as when any of the hybrid materials are subjected to abrasion, the resin between and around the heterogeneous filler-particle distribution is lost, leading to protruding filler particles. Over time, the entire filler particles are plucked out creating bumps and craters and a highly roughened surface. ${ }^{[30]}$ There are a few limitations of this in vitro study; the wear of materials was analyzed in the laboratory set up where oral environment could not be simulated. This study was limited to abrasive wear. Clinically, toothbrushing may affect the rate of abrasive wear depending on hardness of bristles and abrasiveness of dentifrices. The variations and complexity of oral environment may affect the wear behaviors and clinical performance of restorative materials.

\section{CONCLUSIONS}

The structure and composition of composites and compomer materials, in particular, the matrix characteristics, type of filler, and filler-particle size greatly affect the wear resistance. FTIR along with PCA/CA confirmed structural changes and revealed information about chemical groups prone to bring change in materials properties. Greatest mass loss was reported by Z250 while SDR suffered the minimum mass loss. The smoothest surface was demonstrated by the Dyract while the roughest surface was that of Z250. AFM and Optical profilometer can be used in tandem for roughness analysis and correlation between these techniques are highly significant, where AFM offered a higher precision at a nanoscale level.

\section{Acknowledgment}

The authors would like to acknowledge IRCBM, Comsats, Pakistan, for providing facilities to conduct this study.

\section{Financial support and sponsorship \\ Nil.}

\section{Conflicts of interest}

There are no conflicts of interest.

\section{REFERENCES}

1. Jain V, Platt JA, Moore BK, Borges GA. In vitro wear of new indirect resin composites. Oper Dent 2009;34:423-8.

2. Leal A, Paula A, Ramalho A, Esteves M, Ferreira MM, Carrilho E, et al Roughness and microhardness of composites after different bleaching techniques. J Appl Biomater Funct Mater 2015;13:e381-8.

3. Giacomelli L, Derchi G, Frustaci A, Orlando B, Covani U, Barone A, et al. Surface roughness of commercial composites after different polishing protocols: An analysis with atomic force microscopy. Open Dent J 2010;4:191-4.

4. Cao L, Zhao X, Gong X, Zhao S. An in vitro investigation of wear resistance and hardness of composite resins. Int J Clin Exp Med 2013;6:423-30.

5. Johansson A, Johansson AK, Omar R, Carlsson GE. Rehabilitation of the worn dentition. J Oral Rehabil 2008;35:548-66.

6. Hahnel S, Schultz S, Trempler C, Ach B, Handel G, Rosentritt M, et al. Two-body wear of dental restorative materials. J Mech Behav Biomed Mater 2011;4:237-44.

7. Han JM, Zhang H, Choe HS, Lin H, Zheng G, Hong G, et al. Abrasive wear and surface roughness of contemporary dental composite resin. Dent Mater J 2014;33:725-32.

8. Cramer NB, Stansbury JW, Bowman CN. Recent advances and developments in composite dental restorative materials. J Dent Res 2011;90:402-16.

9. De Souza GM. Nanoparticles in restorative materials. Nanotechnology in Endodontics. Cham, Switzerland: Springer; 2015. p. 139-71.

10. Toledano M, Osorio R. New advanced materials for high performance at the resin-dentine interface. In: Deb S, editor. Biomaterials for Oral 
and Craniomaxillofacial Applications. Basel, Switzerland: Karger Publishers; 2015. p. 39-48.

11. Al Khuraif AA. An in vitro evaluation of wear and surface roughness of particulate filler composite resin after tooth brushing. Acta Odontol Scand 2014;72:977-83.

12. Roselino Lde M, Chinelatti MA, Alandia-Román CC, Pires-de-Souza Fde C. Effect of brushing time and dentifrice abrasiveness on color change and surface roughness of resin composites. Braz Dent J 2015;26:507-13.

13. Chimello DT, Dibb RG, Corona SA, Lara E. Assessing wear and surface roughness of different composite resins after toothbrushing. Mater Res 2001;4:285-9.

14. Opdam NJ, van de Sande FH, Bronkhorst E, Cenci MS, Bottenberg P, Pallesen $\mathrm{U}$, et al. Longevity of posterior composite restorations: A systematic review and meta-analysis. J Dent Res 2014;93:943-9.

15. Choi MS, Lee YK, Lim BS, Rhee SH, Yang HC. Changes in surface characteristics of dental resin composites after polishing. J Mater Sci Mater Med 2005;16:347-53.

16. García-Contreras R, Scougall-Vilchis R, Acosta-Torres L, Arenas-Arrocena C, García-Garduño R, de la Fuente-Hernández J. Vickers microhardness comparison of 4 composite resins with different types of filler. J Oral Res 2015;4:313-20.

17. Ilie N, Bucuta S, Draenert M. Bulk-fill resin-based composites: An in vitro assessment of their mechanical performance. Oper Dent 2013;38:618-25.

18. Wang LK, Shi LS, Zhu HS. An in vitro investigation of wear resistance and hardness of three kinds of new composite resins. Hua Xi Kou Qiang Yi Xue Za Zhi 2008;26:15-8.

19. Oliveira GU, Mondelli RF, Charantola Rodrigues M, Franco EB, Ishikiriama SK, Wang L, et al. Impact of filler size and distribution on roughness and wear of composite resin after simulated toothbrushing. J Appl Oral Sci 2012;20:510-6.

20. Boaro LC, Gonçalves F, Guimarães TC, Ferracane JL, Pfeifer CS, Braga RR. Sorption, solubility, shrinkage and mechanical properties of "low-shrinkage" commercial resin composites. Dent Mater 2013;29:398-404.

21. Kaleem M, Khan AS, Rehman IU, Wong FS. Effect of beverages on viscoelastic properties of resin-based dental composites. Materials 2015;8:2863-72

22. Gan SN, Kasim NH, Alsanabana F, Radzi ZB, Yahya NA. Polyurethane Oligomers for Use in Restorative Dentistry. Google Patents; 2014.

23. Lim BS, Ferracane JL, Condon JR, Adey JD. Effect of filler fraction and filler surface treatment on wear of microfilled composites. Dent Mater 2002;18:1-1.

24. Kovaříková I, Szewczyková B, Blaškoviš P, Hodúlová E, Lechovič E. Study and characteristic of abrasive wear mechanisms. Mater Sci Technol 2015;1:1335-9053.

25. Turssi CP, Ferracane JL, Vogel K. Filler features and their effects on wear and degree of conversion of particulate dental resin composites. Biomaterials 2005;26:4932-7.

26. Zafar MS, Ahmed N. Effects of wear on hardness and stiffness of restorative dental materials. Life Sci J 2014;11:11-8.

27. Najeeb S, Khurshid Z, Zafar MS, Khan AS, Zohaib S, Martí JM, et al. Modifications in glass ionomer cements: Nano-sized fillers and bioactive nanoceramics. Int J Mol Sci 2016;17:1134.

28. Rizvi A, Zafar MS, Al-Wasifi Y, Fareed W, Khurshid Z. Role of enamel deminerlization and remineralization on microtensile bond strength of resin composite. Eur J Dent 2016;10:376-80.

29. Ferreira PM, Souto SH, Borges BC, de Assunção IV, da Costa GD. Impact of a novel polishing method on the surface roughness and micromorphology of nanofilled and microhybrid composite resins. Rev Port Estomatol Med Dent Cir Maxilofac 2015;56:18-24.

30. Rodrigues-Junior SA, Chemin P, Piaia PP, Ferracane JL. Surface roughness and gloss of actual composites as polished with different polishing systems. Oper Dent 2015;40:418-29. 